\title{
ADDITION OF NUCLEOPHILE TO BENT BONDS OF THE CARBONYL GROUP
}

\author{
V. Gineitytè \\ Institute of Theoretical Physics and Astronomy of Vilnius University, A. Goštauto 12, LT-01108 Vilnius, Lithuania \\ E-mail: gineityte@itpa.lt
}

Received 26 February 2009; revised 27 October 2009; accepted 18 December 2009

\begin{abstract}
Bimolecular nucleophilic addition $\left(\mathrm{Ad}_{\mathrm{N}} 2\right)$ reactions of carbonyl compounds are modelled and studied using the semilocalized approach to chemical reactivity suggested previously. The approach consists in the direct obtaining of the one-electron density matrix of the whole reacting system in the form of a power series in the basis of orbitals localized on separate bonds. The double $\mathrm{C}=\mathrm{O}$ bond is represented by two equivalent bent bonds, one of them being under attack of a nucleophile. The results support the previous hypothesis about an increasing polarity of the $\mathrm{C}=\mathrm{O}$ bond under the influence of an external cation attached to a lone electron pair of the oxygen atom and yield a new interpretation of this effect in terms of interorbital interactions. Coordination of the oxygen atom by a subsidiary cation is shown to ensure also an increase of charge transfer from nucleophile to the reacting $\mathrm{C}-\mathrm{O}$ bond at later stages of the process. These results serve to account for the known catalytic effect of acids in $\operatorname{Ad}_{N} 2$ reactions. Effects of substituents of various types upon the same charge transfer are explored and interpreted too. A certain analogy is concluded between early stages of the reaction under study and of the $\mathrm{S}_{\mathrm{N}} 2$ process of alkyl halogenides. Advantages of the bent bond model of the $\mathrm{C}=\mathrm{O}$ bond versus the usual $\sigma, \pi$-model are discussed in respect of interpretation of chemical reactivity.
\end{abstract}

Keywords: bimolecular nucleophilic addition, carbonyl compounds, the bent bond model, chemical reactivity, bond orbitals

PACS: 31.15.-p, 31.15.X-, 31.15.xp

\section{Introduction}

Two principal ways of investigation reveal themselves in the theory of chemical reactions. The first one coincides with applications of various numerical methods to find critical points within potential energy surfaces of reacting systems and to establish the corresponding spatial structures. This approach is orientated mostly to studies of individual reactions, wherein both the constitution of initial compounds and external conditions of the process are specified. Calculated critical energies are then directly comparable to the relevant experimental data.

The second way consists in constructing abstract and/or general models intended for embracing all reactions of a certain type in accordance with their chemical classification. Models of various degrees of sophistication are possible starting with verbal discussions of principal interorbital interactions governing the reaction and ending with applications of involved mathematical methods in the framework of the Hückel type approximation. Graph-theoretical and topological methods [1,2] and the perturbation theory [3-5] are most commonly used in the latter case. Details of specific systems usually are ignored when constructing models and this fact makes a direct comparison of resulting conclusions to experimental data somewhat difficult. The abstract models, however, acquire essential advantages over numerical calculations in respect of feasibility of direct comparisons of distinct chemical systems. Moreover, models allow us to reveal nontrivial relations between different characteristics of a certain process (e. g. static and dynamic criteria of relative reactivity) and to interpret these characteristics in a simple and unified manner (e.g. in terms of orbitals and their interactions). Finally, employment of 'purely theoretical' characteristics (such as populations of separate orbitals) instead of critical energies makes the above-anticipated relations more easily obtainable and expressible. This implies the abstract models are a complementary alternative to numerical calculations.

Bimolecular nucleophilic addition $\left(\operatorname{Ad}_{\mathrm{N}} 2\right)$ reactions of carbonyl compounds [6-8] are among popular organic processes. These reactions are of great significance for synthesis [7] and therefore are studied experimentally up to now [9-12]. Quantum chemical 
calculations of potential energy surfaces of specific representatives of $\mathrm{Ad}_{\mathrm{N}} 2$ processes are also performed and analysed [13-17]. Discussions of some general aspects of these reactions on the basis of the standard $\sigma, \pi$ model for double bonds may be found in Refs. [3,68]. This popular model, however, encounters significant difficulties in representing the effects of neighbouring groups upon the relative reactivity of the $\mathrm{C}=\mathrm{O}$ bond and in comparing the $\mathrm{Ad}_{\mathrm{N}} 2$ processes of carbonyl compounds to related reactions.

To discuss these points in a more detail, let us start with the relevant experimental facts. The reagent (nucleophile) is known to be always added to the carbon atom of the $\mathrm{C}=\mathrm{O}$ bond [6-8] during the $\mathrm{Ad}_{\mathrm{N}} 2$ reaction. For different carbonyl compounds, however, relative reactivities of this atom towards a certain nucleophile $(\mathrm{N} u)$ largely depend on the structure of the nearest environment. In particular, an enhanced reactivity of the carbonyl group is observed if the oxygen atom is coordinated by a subsidiary cation (electrophile) [7]. This effect forms the basis of the practically important catalysis of the $\mathrm{Ad}_{\mathrm{N}} 2$ processes by acids. An analogous growth of the relative reactivity of the $\mathrm{C}=\mathrm{O}$ bond follows also after introducing an electron-accepting substituent into the nearest neighbourhood of its carbon atom $[6,8]$. Meanwhile, electron-donating substituents determine suppressed reactivities of respective carbonyl compounds [7]. Finally, the above-enumerated effects closely resemble those peculiar to the bimolecular nucleophilic substitution $\left(\mathrm{S}_{\mathrm{N}} 2\right)$ processes of alkyl halogenides [8]. As for instance, the rate-accelerating influence of electron-accepting substituents is observed in the $\mathrm{S}_{\mathrm{N}} 2$ reactions too (cf. the enhanced reactivity of $\alpha$-halocarbonyl compounds versus respective alkyl and allyl halogenides [18]). These facts form the basis of the analogy between early stages of $\mathrm{Ad}_{\mathrm{N}} 2$ and $\mathrm{S}_{\mathrm{N}} 2$ reactions [8]. So far as the usual $\sigma, \pi$-model of double bonds is concerned, distinct orbitals ( $\sigma$ and $\pi$ ) are used to represent the $\mathrm{C}=\mathrm{O}$ bond. Orbitals of the reaction centre (i.e. the $\pi$ orbitals of the $\mathrm{C}=\mathrm{O}$ bond) and those of fragments under our interest (viz. of the subsidiary cation attached to the $\sigma$-electron lone pair of the oxygen atom and/or of a substituent described by a $\sigma$-inductive effect) are mutually orthogonal in this model. This implies an absence of resonance parameters between orbitals of the above-specified subsystems and thereby of intersubsystem interaction in the framework of the Hückel type approximation. That is why the above-described difficulties arise.

To circumvent these difficulties, a subsidiary hypothesis is usually introduced about a growing abso- lute value of the Coulomb parameter $\left(\alpha_{\mathrm{o}}\right)$ of the $2 \mathrm{p}_{z}$ $\mathrm{AO}$ of the oxygen atom under influence of an external cation attached to its $\sigma$-electron lone pair [3]. Such an alteration in the $\alpha_{\mathrm{o}}$ value is traced back to manifestation of Coulomb forces. As a result, a higher polarity of the $\pi$-bond is expected after coordination of the oxygen atom and this serves to account for the enhanced relative reactivity of the whole $\mathrm{C}=\mathrm{O}$ group. The abovementioned hypothesis, however, implies a strong interaction between the $\sigma$ - and $\pi$-orbitals of the $\mathrm{C}=\mathrm{O}$ bond. Thus, it is not consistent with the very concept of quasiindependent $\sigma$ - and $\pi$ - subsystems underlying the standard model.

The aim of the present study consists in constructing an adequate abstract model of $\mathrm{Ad}_{\mathrm{N}} 2$ reactions of carbonyl compounds and in its applications to analyse the effects of neighbouring groups upon characteristics of the reacting $\mathrm{C}=\mathrm{O}$ bond, as well as to compare early stages of $\mathrm{Ad}_{\mathrm{N}} 2$ and $\mathrm{S}_{\mathrm{N}} 2$ reactions. To this end, we will invoke the semilocalized approach to chemical reactivity suggested recently $[19,20]$. The approach is based on the direct obtaining of the one-electron density matrix (DM) of the whole reacting system by means of solution of the so-called commutation equation in the form of power series [21]. The Hückel type approximation is invoked for Hamiltonian matrix elements in addition. Orbitals localized on separate fragments of both participants of the process are used as basis functions there. Bonding and antibonding orbitals of individual chemical bonds usually play this role along with orbitals of other fragments, e. g. of phenyl rings. Separate members of the above-mentioned series, in turn, are expressible in terms of direct and indirect interactions of basis orbitals. In our context, the most attractive feature of the approach consists in the fact that local electron density redistributions only between orbitals of the reacting fragments (reaction centre) are described by lower order terms of the series, whilst those embracing their neighbourhoods (e. g. substituents) are represented by higher order terms. As a result, the approach was shown to yield successful interpretations of neighbourhood-determined aspects of related processes, e. g. of $\mathrm{S}_{\mathrm{N}} 2$ reactions of substituted alkanes [22] and $\alpha$-halocarbonyl compounds [23], of the addition reactions to butadiene and substituted ethenes [24], etc. Difficulties originating from the $\sigma, \pi$-representation of double bonds, however, still remain in this approach.

In this connection, we are about to invoke also an alternative bent bond model of double bonds [18, 25-29]. Atoms involved in the bond concerned are represented by $\mathrm{sp}^{3}$-hybrid AOs (HAOs) in this model in contrast to 
the above-considered one. Thereupon, two equivalent bent bonds are formed from two pairs of these HAOs. Numerous advantages of this alternative model versus the usual one are known and this comparative discussion still continues $[18,27]$. The majority of these advantages refer just to qualitative investigations. In particular, the bent bond model allows the internuclear distances and acidities of hydrogen atoms to be predicted more successfully in the simplest hydrocarbons [25]. The same refers also to photoelectron spectra of strained alkanes [29]. The fact that the alternative model and not the standard one has been supported by accurate numerical calculations of electron density distribution [3034] also deserves mentioning here. In our context, the most important attractive feature of bent bonds consists in non-zero resonance parameters between respective bond orbitals both inside the double bond and between the latter and other fragments, in contrast to the abovediscussed $\sigma, \pi$-model. (Let us recall here that non-zero resonance parameters always arise between pairs of $\mathrm{sp}^{3}$ HAOs of the same atom owing to different one-electron energies of $2 \mathrm{~s}$ and $2 \mathrm{p}$ AOs [35-37].) Thus, the model of $\operatorname{Ad}_{\mathrm{N}} 2$ reactions to be suggested in the present study is based on a certain combination of the semilocalized approach of Refs. $[19,20]$ and of the bent bond model for the $\mathrm{C}=\mathrm{O}$ bond.

The paper is organized as follows: Section 2 contains an overview of the principal expressions of the semilocalized approach. The subsequent study starts with verification of the hypothesis about an increasing polarity of the $\mathrm{C}=\mathrm{O}$ bond under influence of coordination of the oxygen atom by a subsidiary cation using the abovespecified combined approach (Section 3). The remaining sections (4 and 5) are devoted to investigation of the very addition process of nucleophile. Section 4 addresses the influence of the subsidiary cation upon the relative reactivity of the $\mathrm{C}=\mathrm{O}$ bond, whilst Section 5 contains an analogous study of effects of substituents.

\section{The principal expressions of the semilocalized approach to chemical reactivity}

Let our reacting system consist of a certain number of more or less localized chemical bonds and lone electron pairs. This implies that interbond resonance parameters of our system are first order terms as compared to the intrabond ones [35] in the basis of HAOs and $1 \mathrm{~s}_{\mathrm{H}}$ AOs, the latter representing the hydrogen atoms. After passing to linear combinations of pairs of the above-specified orbitals pertinent to individual bonds (see Eq. (9) given below), a new basis of bond orbitals
(BOs) $\{\varphi\}$ may be defined. In the case of a lone electron pair, the relevant bonding $\mathrm{BO}$ coincides with the respective HAO [38]. Finally, the bonding BOs (BBOs) and the antibonding $\mathrm{BOs}(\mathrm{ABOs})$ are assumed to be initially-occupied and initially-vacant, respectively. In this connection, these BOs will be correspondingly distinguished by subscripts (+) and (-), e. g. $\varphi_{(+) i}, \varphi_{(-) j}$, etc, where $i$ and $j$ represent individual orbitals. Oneelectron energies of these BOs will be accordingly denoted by $\varepsilon_{(+) i}, \varepsilon_{(-) j}$, etc.

The one-electron DM of the reacting system has been represented in the semilocalized approach in terms of partial populations $\left(q_{(+) i,(-) j}\right)$ transferred between orbitals (BOs) of opposite initial occupation $\left(\varphi_{(+) i}\right.$ and $\left.\varphi_{(-) j}\right)$ due to interbond interaction. For any population $q_{(+) i,(-) j}$, members of the relevant power series have been expressed in terms of elements of certain principal matrices $G_{(k)}, k=1,2,3, \ldots$ specified below and describing direct and indirect interactions between BOs ( $k=1,2,3, \ldots$ stands for the order parameter). The first three non-zero increments $q_{(+) i,(-) j}^{(k)}$ of the series for $q_{(+) i,(-) j}$ take the form

$$
q_{(+) i,(-) j}^{(2)}=2\left(G_{(1) i j}\right)^{2},
$$

$q_{(+) i,(-) j}^{(3)}=4 G_{(1) i j} G_{(2) i j}$,

$$
\begin{aligned}
q_{(+) i,(-) j}^{(4)}= & 4 G_{(1) i j}\left[G_{(3) i j}+\frac{1}{2}\left(G_{(1)} G_{(1)}^{+} G_{(1)}\right)_{i j}\right] \\
& +2\left(G_{(2) i j}\right)^{2} .
\end{aligned}
$$

Let us introduce the following notations for interactions (resonance parameters) between BOs:

$$
\begin{aligned}
S_{i m} & =\left\langle\varphi_{(+) i}|\widehat{H}| \varphi_{(+) m}\right\rangle, \\
R_{i j} & =\left\langle\varphi_{(+) i}|\widehat{H}| \varphi_{(-) j}\right\rangle, \\
Q_{j r} & =\left\langle\varphi_{(-) j}|\widehat{H}| \varphi_{(-) r}\right\rangle,
\end{aligned}
$$

where the respective basis orbitals are indicated inside the bra- and ket-vectors. Then the first order element $G_{(1) i j}$ takes the form

$$
G_{(1) i j}=-\frac{R_{i j}}{\varepsilon_{(+) i}-\varepsilon_{(-) j}}
$$


and describes the direct (through-space) interaction between the $\mathrm{BBO} \varphi_{(+) i}$ and the $\mathrm{ABO} \varphi_{(-) j}$. The second order element $G_{(2) i j}$ is expressed as

$$
\begin{aligned}
& G_{(2) i j}=\frac{1}{\varepsilon_{(+) i}-\varepsilon_{(-) j}} \\
& \times\left\{\sum_{m}^{\mathrm{BBO}} \frac{S_{i m} R_{m j}}{\varepsilon_{(+) m}-\varepsilon_{(-) j}}-\sum_{r}^{\mathrm{ABOs}} \frac{R_{i r} Q_{r j}}{\varepsilon_{(+) i}-\varepsilon_{(-) r}}\right\}
\end{aligned}
$$

and represents the indirect interaction between the same orbitals $\left(\varphi_{(+) i}\right.$ and $\left.\varphi_{(-) j}\right)$ by means of a single mediator. It is seen that both BBOs $\left(\varphi_{(+) m}\right)$ and ABOs $\left(\varphi_{(-) r}\right)$ are able to play this role. Similarly, the element $G_{(3) i j}$ describes the indirect interaction between $\varphi_{(+) i}$ and $\varphi_{(-) j}$ by means of two mediators. The relevant expression is as follows [24]:

$$
\begin{aligned}
& G_{(3) i j}=\frac{-1}{\varepsilon_{(+) i}-\varepsilon_{(-) j}} \\
& \times\left\{\sum_{n}^{\text {BBOs BBOs }} \sum_{m} \frac{S_{i n} S_{n m} R_{m j}}{\left(\varepsilon_{(+) n}-\varepsilon_{(-) j}\right)\left(\varepsilon_{(+) m}-\varepsilon_{(-) j}\right)}\right. \\
& -\sum_{n}^{\text {BBOs ABOs }} \sum_{r}\left[\frac{S_{i n} R_{n r} Q_{r j}}{\left(\varepsilon_{(+) n}-\varepsilon_{(-) j}\right)\left(\varepsilon_{(+) n}-\varepsilon_{(-) r}\right)}\right. \\
& +\frac{S_{i n} R_{n r} Q_{r j}}{\left(\varepsilon_{(+) i}-\varepsilon_{(-) r}\right)\left(\varepsilon_{(+) n}-\varepsilon_{(-) r}\right)} \\
& +\frac{R_{i r} R_{r n}^{+} R_{n j}}{\left(\varepsilon_{(+) n}-\varepsilon_{(-) r}\right)\left(\varepsilon_{(+) n}-\varepsilon_{(-) j}\right)} \\
& \left.+\frac{R_{i r} R_{r n}^{+} R_{n j}}{\left(\varepsilon_{(+) i}-\varepsilon_{(-) r}\right)\left(\varepsilon_{(+) n}-\varepsilon_{(-) r}\right)}\right]+ \\
& \left.+\sum_{p}^{\mathrm{ABOs} \mathrm{ABOs}} \frac{R_{i r} Q_{r p} Q_{p j}}{\left(\varepsilon_{(+) i}-\varepsilon_{(-) p}\right)\left(\varepsilon_{(+) i}-\varepsilon_{(-) r}\right)}\right\} .
\end{aligned}
$$

Pairs of mutually overlapping orbitals situated in between the orbitals $\varphi_{(+) i}$ and $\varphi_{(-) j}$ are the most efficient mediators of this indirect interaction.

The total energy of the reacting system $(E)$ also takes the form of power series in the semilocalized approach. Moreover, the $k$ th order member of this series $\left(E_{(k)}\right)$ was shown to be related to respective increments to the partial transferred populations [39], viz.

$$
E_{(k)}=\frac{1}{k-1} \sum_{i}^{\text {BBOs }} \sum_{j}^{\mathrm{ABOs}} q_{(+) i,(-) j}^{(k)}\left(\varepsilon_{(+) i}-\varepsilon_{(-) j}\right) .
$$

This simple relation indicates that the more population is transferred from BBOs to $\mathrm{ABOs}$, the more stabilized the interacting system becomes. Thus, we may confine ourselves to comparison of transferred populations in the case of related systems characterized by coinciding one-electron energies of BOs. From Eqs. (5)-(7) it follows also that emergence either of new resonance parameters (e.g. of those representing the intermolecular interaction between the reactant and the reagent) or of additional orbitals (as it is the case with coordination of the oxygen atom by a subsidiary cation) gives birth to new terms in the interorbital interactions $G_{(k) i j}$ and thereby to new contributions to the partial transferred populations $q_{(+) i,(-) j}^{(k)}$. Comparison of these additional increments usually proves to be sufficient in qualitative investigations.

The above-discussed interbond charge transfer (represented by partial transferred populations $\left.q_{(+) i,(-) j}\right)$ evidently is accompanied by deoccupation of BBOs and by an additional occupation of ABOs of individual bonds. That is why alterations arise in the intrabond characteristics too. To consider the expressions concerned, let us dwell on the case of a heteropolar (heteroatom-containing) bond. The relevant two atoms will be designated by $\mathrm{Z}$ and $\mathrm{C}$, where $\mathrm{Z}$ stands for a more electronegative heteroatom. Let the bond under study coincide with the $I$ th bond of our system. The HAOs ascribed to atoms $\mathrm{Z}$ and $\mathrm{C}$, respectively, will be denoted by $\chi_{I Z}$ and $\chi_{I C}$. These orbitals will be represented by Coulomb parameters $\alpha_{\mathrm{Z}}$ and $\alpha_{\mathrm{C}}$, whereas the bond itself will be characterized by resonance parameter $\beta_{I}$. The equalities $\alpha_{\mathrm{C}}=0$ and $\beta_{I}=1$ will be accepted further for convenience. Owing to the higher electronegativity of the atom $\mathrm{Z}$ versus that of the carbon atom, the parameter $\alpha_{\mathrm{Z}}$ is supposed to be positive in the above-specified energy units. The structure of the remaining part of the system under study is not essential here. The $\mathrm{BBO}$ of the $I$ th bond $\varphi_{(+) i}$ and the respective $\operatorname{ABO} \varphi_{(-) i}$ will be defined as follows:

$$
\varphi_{(+) i}=a_{I} \chi_{I Z}+b_{I} \chi_{I \mathrm{C}}, \quad \varphi_{(-) i}=b_{I} \chi_{I Z}-a_{I} \chi_{I \mathrm{C}},
$$

where the coefficients $a_{I}$ and $b_{I}$ are [40]

$$
a_{I}=\cos \frac{\gamma_{I}}{2}, \quad b_{I}=\sin \frac{\gamma_{I}}{2}, \quad a_{I}>b_{I}>0
$$

and

$$
\gamma_{I}=\arctan \frac{2}{\alpha_{\mathrm{Z}}}, \quad 0 \leq \gamma_{I} \leq \frac{\pi}{2} .
$$

(Note that the upper limit $\gamma_{I}=\pi / 2$ refers to the particular case of a $\mathrm{C}-\mathrm{C}$ bond.) 
Expressions for occupation numbers of orbitals $\chi_{I Z}$ and $\chi_{I C}$ may be found in Ref. [40]. Dipole-like increments of these expressions are sufficient for our study. Thus, let us confine ourselves here just to these increments. The only zero order term of this type coincides with $\pm \cos \gamma_{I}$, where $\gamma_{I}$ is defined by Eq. (11) and the upper and the lower signs correspondingly refer to HAOs $\chi_{I Z}$ and $\chi_{I C}$. This term represents the socalled primary dipole of the given bond that does not depend on the structure of the remaining part of the system. The neighbourhood-dependent part of the overall polarity of the $I$ th bond, in turn, is represented by two second order terms. The first one (the so-called polarization increment $\left.\pm p_{(2) I}\right)$ describes the induced dipole of the Ith bond due to the very presence of other bonds (lone pairs). This term is expressible as follows:

$$
p_{(2) I}=-2 G_{(2) i i} \sin \gamma_{I} .
$$

Additivity of the matrix element $G_{(2) i i}$ with respect to mediators (see Eq. (6)) allows the polarization dipole $p_{(2) I}$ of the $I$ th bond to be expressed as a sum of partial increments of other bonds (lone pairs). The sign of such an increment depends on relative values and signs of resonance parameters involved and cannot be defined $a$ priori (differences in one-electron energies of BOs contained within Eq. (6) are positive in our energy units). The second increment to the overall polarity of the $I$ th bond $\left( \pm d_{(2) I}\right)$ is related to the non-uniform distribution among the basis functions $\chi_{I Z}$ and $\chi_{I C}$ both of the population lost by the BBO $\varphi_{(+) i}$ and of that acquired by the $\operatorname{ABO} \varphi_{(-) i}$ of the $I$ th bond. This term has been expressed as follows [40]:

$$
d_{(2) I}=-\sum_{j}\left[\left(G_{(1) j i}\right)^{2}+\left(G_{(1) i j}\right)^{2}\right] \cos \gamma_{I} .
$$

Additive nature of the total dipole $d_{(2) I}$ with respect to contributions of various bonds of the molecule is also seen from Eq. (13). Moreover, an a priori negative sign of the contribution $d_{(2) I}$ follows. This implies a consequent reduction of the primary dipole of our bond. In this connection, $d_{(2) I}$ has been called the depolarization dipole. Opposite signs of the primary dipole and of the depolarization one may be accounted for by the nature of the above-mentioned charge redistribution. Indeed, the additional population acquired by the $\mathrm{ABO} \varphi_{(-) i}$ becomes localized mainly on the orbital $\chi_{I C}$ of the carbon atom. In turn, the loss of population of the BBO $\varphi_{(+) i}$ gives rise to a larger reduction of the occupation number of the $\mathrm{AO} \chi_{I Z}$ of the heteroatom $\mathrm{Z}$ as compared to that of the orbital $\chi_{I C}$ of the carbon atom C. Both of these effects contribute to reduction of the primary dipole.

\section{The influence of a subsidiary cation upon the overall polarity of the $\mathrm{C}=\mathrm{O}$ bond}

Let us start with the model of the initial $\mathrm{C}=\mathrm{O}$ bond. Let our system of coordinates to be chosen so that the $y$ axis embraces both carbon and oxygen atoms (Fig. 1). These atoms will be accordingly characterized by quartets of HAOs $\left\{\chi_{\mathrm{C} m}\right\}$ and $\left\{\chi_{\mathrm{O} m}\right\}$, where $m=1,2,3,4$. Orbitals represented by $m=1$ and $m=2$ will be placed on the $z y$ plane, whereas those corresponding to $m=3$ and $m=4$ are positioned on the $x y$ plane. Let the former two pairs of HAOs (i.e. $\chi_{\mathrm{C} 1}, \chi_{\mathrm{O} 1}$ and $\left.\chi_{\mathrm{C} 2}, \chi_{\mathrm{O} 2}\right)$ be involved in the respective bent bonds of our carbonyl group. Numbers $I=1$ and $I=2$ are accordingly ascribed to these bonds. The relevant BBOs and ABOs will be defined by Eqs. (9)-(11), where the oxygen atom plays the role of heteroatom $\mathrm{Z}$. Resonance parameters between HAOs inside the bent bonds will be designated by $\beta_{\mathrm{CO}}$, i. e.

$$
\beta_{\mathrm{CO}}=\left\langle\chi_{\mathrm{C} 1}|\widehat{H}| \chi_{\mathrm{O} 1}\right\rangle=\left\langle\chi_{\mathrm{C} 2}|\widehat{H}| \chi_{\mathrm{O} 2}\right\rangle .
$$

It deserves emphasizing here that the two bent bonds are completely similar in our model. Thus, the BBOs $\varphi_{(+) 1}$ and $\varphi_{(+) 2}$, as well as the ABOs $\varphi_{(-) 1}$ and $\varphi_{(-) 2}$, give birth to pairs of degenerate energy levels (Fig. 2). The remaining HAOs of the carbon $\left(\mathrm{C}_{\alpha}\right)$ atom $\left(\chi_{\mathrm{C} 3}, \chi_{\mathrm{C} 4}\right)$ will be assumed to participate in other bonds including that with the substituent (Section 5), whilst the respective HAOs of the oxygen atom $\left(\chi_{\mathrm{O} 3}, \chi_{\mathrm{O} 4}\right)$ represent the lone pair orbitals of the latter.

Let us turn now to analysis of the influence of a subsidiary cation (electrophile) upon polarities of the above-defined bent bonds. Let this external ion be denoted by $\mathrm{E}^{+}$and represented by an initially-vacant orbital $\chi_{\mathrm{E}}$. This new orbital will be assumed to overlap with the lone pair orbital of the oxygen atom $\chi_{\mathrm{O} 3}$ most significantly so that a large resonance parameter $\beta_{\mathrm{OE}}=\left\langle\chi_{\mathrm{O} 3}|\widehat{H}| \chi_{\mathrm{E}}\right\rangle$ arises (Fig. 1). Thus, let us take this interorbital interaction into our consideration by constructing the bonding combination of orbitals $\chi_{\mathrm{E}}$ and $\chi_{\mathrm{O} 3}$ (denoted by $\varphi_{(+) 3}$ ) and its antibonding counterpart $\left(\varphi_{(-) 3}\right)$ as shown in Eq. (9), where $a_{I}=a_{3}$ and $b_{I}=b_{3}$. The relevant one-electron energies will be designated by $\varepsilon_{(+) 3}$ and $\varepsilon_{(-) 3}$ (Fig. 2). As already mentioned, non-zero resonance parameters represent pairs of HAOs of the same atom [35-37] in contrast to $\sigma$ and 


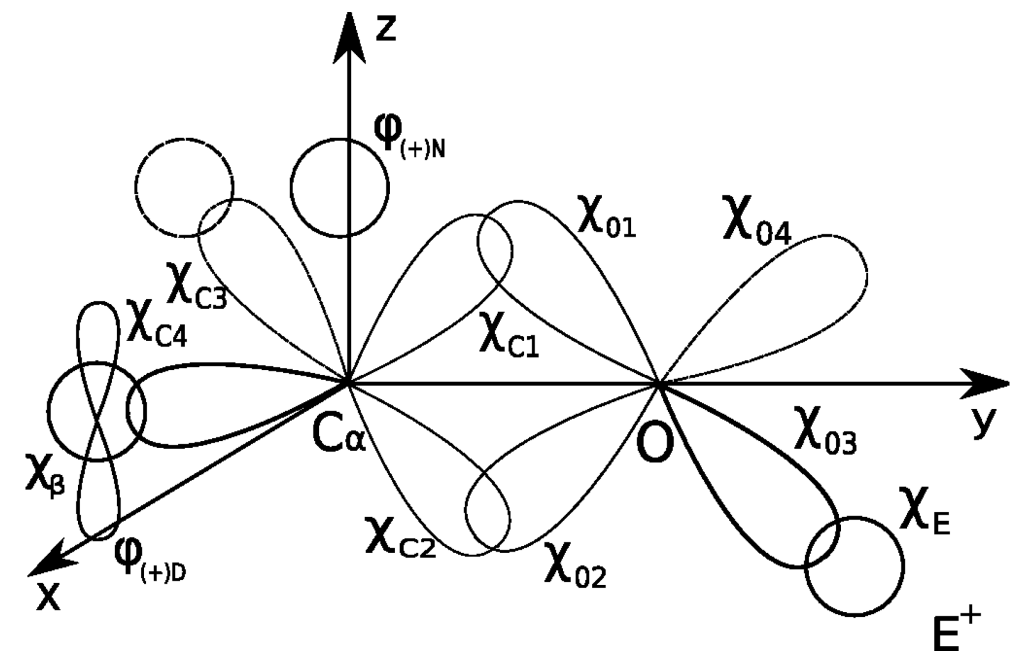

Fig. 1. Basis orbitals underlying the model of a carbonyl compound under attack of nucleophile. The carbon $\left(\mathrm{C}_{\alpha}\right)$ and the oxygen $(\mathrm{O})$ atoms are represented by $\mathrm{sp}^{3}$-hybrid AOs $\chi_{\mathrm{C} m}$ and $\chi_{\mathrm{O} m}$, respectively, where $m=1,2,3,4$. Orbitals $\chi_{\mathrm{E}}$ and $\chi_{\beta}$ correspondingly refer to the subsidiary cation (electrophile) $\mathrm{E}^{+}$and to the $\mathrm{H}_{\beta}$ or $\mathrm{C}_{\beta}$ atom, whilst $\varphi_{(+) \mathrm{N}}$ and $\varphi_{(+) \mathrm{D}}$ represent double-occupied orbitals of nucleophile and of the electron-donating substitutent, respectively.

$$
\begin{aligned}
& \frac{b_{4}^{(p)}-a_{4}^{(p)}}{\varphi_{(-) 4}^{(p)}} \varepsilon_{(-) 4}^{(p)} \\
& \frac{b_{4} \quad-a_{4}}{\varphi_{(-) 4}} \varepsilon_{(-) 4}^{(z)} \\
& \frac{-a_{1} \quad b_{1}}{\overline{\overline{\varphi_{(-) 1}, \varphi_{(-) 2}}}}{ }_{\varepsilon_{(-) 2}}^{\varepsilon_{(-)}} \\
& \overline{\varphi_{(+) \mathrm{N}}} \alpha_{\mathrm{N}}
\end{aligned}
$$

$$
\begin{aligned}
& \frac{a_{4}^{(p)} b_{4}^{(p)}}{\varphi_{(+) 4}^{(p)}} \varepsilon_{(+) 4}^{(p)} \\
& \stackrel{a_{4}}{\bar{\varphi}_{(+) 4}-b_{4}} \varepsilon_{(+) 4}^{(z)}
\end{aligned}
$$

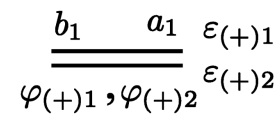
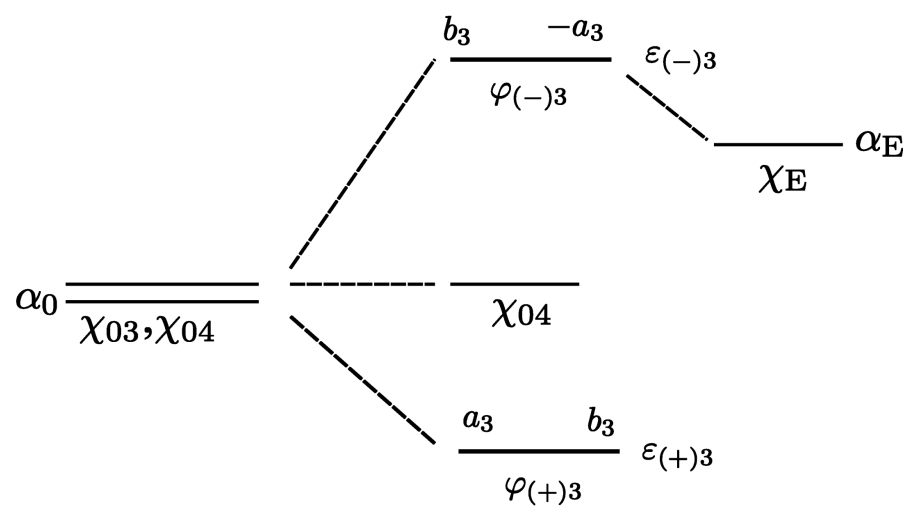

0
$\mathrm{E}^{+}$

Fig. 2. Scheme representing the formation of two-centre bond orbitals of a carbonyl coumpound under attack of nucleophile. Notations $\chi_{03}$, $\chi_{\mathrm{O} 4}, \chi_{\mathrm{E}}, \varphi_{(+) \mathrm{N}}$ stand for initial basis orbitals ( $\mathrm{sp}^{3}$-hybrid AOs (HAOs)) shown in Fig. 1 . These orbitals are additionally characterized by Coulomb parameters $\alpha_{\mathrm{O}}, \alpha_{\mathrm{E}}$, and $\alpha_{\mathrm{N}}$. Newly-formed bonding orbitals of separate bonds are denoted by $\varphi_{(+) i}(i=1,2,3,4)$, whilst their antibonding counterparts are accordingly designated by $\varphi_{(-) i}$. The relevant one-electron energies coincide with $\varepsilon_{(+) i}$ and $\varepsilon_{(-) i}$, respectively. The superscripts $(\mathrm{p})$ and $(\mathrm{Z})$ correspond to the parent $\mathrm{H}-\mathrm{C}_{\alpha}\left(\mathrm{C}_{\alpha}-\mathrm{C}_{\beta}\right)$ bond and to the heteroatom-containing (Z-C $\left.\mathrm{C}_{\alpha}\right)$ bond. Notations $a_{i}$ and $b_{i}$ represent the coefficients at separate HAOs in the final bond orbitals.

$\pi$ orbitals. Let the resonance parameter referring to any pair of HAOs of the oxygen atom be denoted by $\sigma_{\mathrm{O}}$, i. e.

$$
\begin{aligned}
\sigma_{\mathrm{O}}=\left\langle\chi_{\mathrm{O} 1}|\widehat{H}| \chi_{\mathrm{O} 2}\right\rangle & =\left\langle\chi_{\mathrm{O} 1}|\widehat{H}| \chi_{\mathrm{O} 3}\right\rangle= \\
\left\langle\chi_{\mathrm{O} 2}|\widehat{H}| \chi_{\mathrm{O} 3}\right\rangle & =\ldots
\end{aligned}
$$

It is evident that just the parameter $\sigma_{\mathrm{O}}$ represents the interaction between bent bonds and lone pair orbitals of the oxygen atom. Moreover, it is this parameter that is expected to be responsible for the possible influence of coordination of the orbital $\chi_{\mathrm{O} 3}$ by the cation $\mathrm{E}^{+}$upon the overall polarity of the $\mathrm{C}=\mathrm{O}$ bond.

To consider this point in a more detail, let us turn to the dipole-like increments $p_{(2) I}$ and $d_{(2) I}$ of Eqs. (12) and (13) and compare them for the cases of an isolated lone electron pair and of a coordinated one. Inasmuch as the effects of electrophile $\left(\mathrm{E}^{+}\right)$upon properties of both bent bonds are anticipated to coincide one with another owing to their symmetric spatial arrangement with respect to the newly-formed BOs $\varphi_{(+) 3}$ and $\varphi_{(-) 3}$, 
we may confine ourselves to consideration of a single bent bond, e. g. of that between HAOs $\chi_{\mathrm{C} 1}$ and $\chi_{\mathrm{O} 1}$.

Let us start with the case of an isolated lone pair orbital $\chi_{\mathrm{O} 3}$. Contribution of this orbital to the polarization dipole $p_{(2) 1}$ will be denoted by $p_{(2) 1}^{(\mathrm{O} 3)}$. The relevant expression follows from the first fraction of the righthand side of Eq. (6). Similarly, the increment of the same HAO to the depolarization dipole $\left(d_{(2) 1}^{(\mathrm{O} 3)}\right)$ is determined by the $G_{(1) j i}^{2}$-containing term of Eq. (13). The result takes the form

$$
\begin{aligned}
& p_{(2) 1}^{(\mathrm{O} 3)}=-\frac{2 a_{1} b_{1} \sigma_{\mathrm{O}}^{2} \sin \gamma_{1}}{\left(\varepsilon_{(+) 1}-\varepsilon_{(-) 1}\right)\left(\alpha_{\mathrm{O}}-\varepsilon_{(-) 1}\right)}, \\
& d_{(2) 1}^{(\mathrm{O} 3)}=-\frac{b_{1}^{2} \sigma_{\mathrm{O}}^{2} \cos \gamma_{1}}{\left(\alpha_{\mathrm{O}}-\varepsilon_{(-) 1}\right)^{2}},
\end{aligned}
$$

where $\alpha_{\mathrm{O}}$ coincides with the Coulomb parameter of the $\mathrm{HAO} \chi_{\mathrm{O} 3}$. It is seen that both $p_{(2) 1}^{(\mathrm{O} 3)}$ and $d_{(2) 1}^{(\mathrm{O} 3)}$ are negative quantities. The origin of the negative sign of depolarization was explained in Section 2. The same sign of $p_{(2) 1}^{(\mathrm{O} 3)}$ is in line with the expected repulsion between the lone electron pair and the pair of electrons pertinent to our bent bond. On the whole, reduction of the primary polarity of the $\mathrm{C}=\mathrm{O}$ bond under influence of the lone electron pair follows from our model.

Let us turn now to the coordinated lone electron pair. The newly-formed orbitals $\varphi_{(+) 3}$ and $\varphi_{(-) 3}$ play now the role of mediators in the indirect intrabond interaction $G_{(2) 11}$ determining the polarization dipole $p_{(2) 1}$ (see Eq. (12)). Moreover, the electron-donating effect of the former orbital upon the bent bond is now accompanied by a certain electron-accepting effect of the latter. In this connection, let us consider the influences of the $\operatorname{BBO} \varphi_{(+) 3}$ and of the $\operatorname{ABO} \varphi_{(-) 3}$ separately.

The increments of the bonding orbital $\varphi_{(+) 3}$ to the polarization and depolarization dipoles of the 1 st bent bond will be denoted by $p_{(2) 1}^{(+) 3}$ and $d_{(2) 1}^{(+) 3}$, respectively. These are

$$
\begin{aligned}
& p_{(2) 1}^{(+) 3}=-\frac{2 a_{1} b_{1} a_{3}^{2} \sigma_{\mathrm{O}}^{2} \sin \gamma_{1}}{\left(\varepsilon_{(+) 1}-\varepsilon_{(-) 1}\right)\left(\varepsilon_{(+) 3}-\varepsilon_{(-) 1}\right)}, \\
& d_{(2) 1}^{(+) 3}=-\frac{b_{1}^{2} a_{3}^{2} \sigma_{\mathrm{O}}^{2} \cos \gamma_{1}}{\left(\varepsilon_{(+) 3}-\varepsilon_{(-) 1}\right)^{2}}
\end{aligned}
$$

and also prove to be negative quantities. Thus, comparison of absolute values of respective increments of Eqs. (16) and (17) becomes of interest. It is seen that the former energy interval $\alpha_{\mathrm{O}}-\varepsilon_{(-) 1}$ is replaced by a larger one $\left(\varepsilon_{(+) 3}-\varepsilon_{(-) 1}\right)$ and an additional factor $a_{3}^{2}<1$ arises in the numerators of fractions of Eq. (17). Two origins of these alterations may be mentioned: first, the one-electron energy of the lone pair orbital is lowered against its initial value $\left(\alpha_{\mathrm{O}}\right)$ after introducing the electrophile (Fig. 2) and, second, the square of the orbital itself undergoes a shift towards electrophile after formation of the bonding orbital $\varphi_{(+) 3}$. We then obtain

$$
\left|p_{(2) 1}^{(+) 3}\right|<\left|p_{(2) 1}^{(\mathrm{O} 3)}\right|, \quad\left|d_{(2) 1}^{(+) 3}\right|<\left|d_{(2) 1}^{(\mathrm{O} 3)}\right| .
$$

Thus, the suppressing effect of the bonding orbital $\varphi_{(+) 3}$ upon the overall polarity of our bent bond is lower as compared to that of the parent lone pair orbital. This result is in line with our expectation about a lower repulsion between electrons of a coordinated pair and those of a bent bond because of the shift of the former away from the given bond.

Let us turn finally to the relevant increments of the antibonding combination $\varphi_{(-) 3}$ designated by $p_{(2) 1}^{(-) 3}$ and $d_{(2) 1}^{(-) 3}$. These are expressible as follows:

$$
\begin{aligned}
& p_{(2) 1}^{(-) 3}=\frac{2 a_{1} b_{1} b_{3}^{2} \sigma_{\mathrm{O}}^{2} \sin \gamma_{1}}{\left(\varepsilon_{(+) 1}-\varepsilon_{(-) 1}\right)\left(\varepsilon_{(+) 1}-\varepsilon_{(-) 3}\right)}, \\
& d_{(2) 1}^{(-) 3}=-\frac{a_{1}^{2} b_{3}^{2} \sigma_{O}^{2} \cos \gamma_{1}}{\left(\varepsilon_{(+) 1}-\varepsilon_{(-) 3}\right)^{2}} .
\end{aligned}
$$

It is seen that the new polarization component $\left(p_{(2) 1}^{(-) 3}\right)$ acquires a positive sign in contrast to previous ones. This result also causes no surprise as the $\mathrm{ABO} \varphi_{(-) 3}$ largely belongs to the cation $\mathrm{E}^{+}$. Moreover, the increments $p_{(2) 1}^{(-) 3}$ and $d_{(2) 1}^{(-) 3}$ now become of opposite signs and comparison of their absolute values is required to reveal the total effect. The overall situation here closely resembles that observed in the case of a heteroatomcontaining bond attacked by a nucleophile [41]. The above-mentioned comparison also may be carried out by analysis of the ratio between absolute values of $p_{(2) 1}^{(-) 3}$ and $d_{(2) 1}^{(-) 3}$ as described in Ref. [41]. The results allow us then to conclude that the absolute value of the polarization increment $p_{(2) 1}^{(-) 3}$ exceeds that of $d_{(2) 1}^{(-) 3}$ considerably for sufficiently low differences between parameters $\alpha_{\mathrm{O}}$ and $\alpha_{\mathrm{C}}$ versus $\beta_{\mathrm{CO}}$. The carbonyl group was shown to be embraced just by this case [41]. Predominance of the positive increment $p_{(2) 1}^{(-) 3}$ over the negative one $\left(d_{(2) 1}^{(-) 3}\right)$ implies a stimulating effect of the $\mathrm{ABO} \varphi_{(-) 3}$ and thereby of the electrophile itself upon the polarity of the $\mathrm{C}=\mathrm{O}$ bond. 
On the whole, an increased polarity of the $\mathrm{C}=\mathrm{O}$ bond under influence of an external electrophile unambiguosly follows from the above study. Two origins of this effect reveal themselves here: the lowered suppression of the initial polarity of the bond by the lone electron pair after its coordination and the additional dipole induced by the electrophile itself.

\section{The effect of coordination of a lone electron pair of the oxygen atom upon the extent of charge transfer from nucleophile to the $\mathrm{C}=\mathrm{O}$ bond}

Let us turn now to the very addition process between a carbonyl compound and nucleophile. In this connection, the previous model of the reactant (Section 3) will be supplemented with that of the reagent. The latter will be represented by a single initially-occupied orbital as previously [22-24]. Let this orbital be denoted by $\varphi_{(+) \mathrm{N}}$. Inasmuch as nucleophile usually is assumed to attack the carbon atom of the $\mathrm{C}=\mathrm{O}$ bond from above [7], the orbital $\varphi_{(+) \mathrm{N}}$ will be placed on the $z y$ plane of our model (Fig. 1). As a result, this new orbital is supposed to overlap primarily with the HAO $\chi_{\mathrm{C} 1}$ of the first bent bond. The relevant resonance parameter will be denoted by $\tau$, i. e. $\left\langle\varphi_{(+) \mathrm{N}}|\widehat{H}| \chi_{\mathrm{C} 1}\right\rangle=\tau$. Analysis of the effect of the approaching nucleophile upon polarity of any heteroatom-containing bond [41] is now applicable to the above-described model. Consequently, an additional shift of the pair of electrons of the bent bond towards the more electronegative oxygen atom [42] is expected to take place during the addition process to the carbonyl group. In this respect, the analogy is supported between early stages of the $\mathrm{Ad}_{\mathrm{N}} 2$ and $\mathrm{S}_{\mathrm{N}} 2$ reactions [8].

In this section, we are about to explore the effect of coordination of a lone pair orbital of the oxygen atom by a subsidiary cation $\left(\mathrm{E}^{+}\right)$upon the relative reactivity of the $\mathrm{C}=\mathrm{O}$ bond towards the nucleophile. To this end, we will compare the partial transferred populations $q_{(+) \mathrm{N},(-) 1}$ before and after introducing the subsidiary cation $\left(\mathrm{E}^{+}\right)$. Resonance parameters between $\mathrm{BOs}$ required for such a comparison are as follows:

$$
\begin{aligned}
S_{\mathrm{N} 1} & =\left\langle\varphi_{(+) \mathrm{N}}|\widehat{H}| \varphi_{(+) 1}\right\rangle=b_{1} \tau, \\
R_{\mathrm{N} 1} & =\left\langle\varphi_{(+) \mathrm{N}}|\widehat{H}| \varphi_{(-) 1}\right\rangle=-a_{1} \tau, \\
S_{13}^{(\mathrm{O} 3)} & =\left\langle\varphi_{(+) 1}|\widehat{H}| \chi_{\mathrm{O} 3}\right\rangle=a_{1} \sigma_{\mathrm{O}}, \\
R_{31}^{\mathrm{O} 3)} & =\left\langle\chi_{\mathrm{O} 3}|\widehat{H}| \varphi_{(-) 1}\right\rangle=b_{1} \sigma_{\mathrm{O}},
\end{aligned}
$$

$$
\begin{aligned}
& R_{13}^{(-) 3}=\left\langle\varphi_{(+) 1}|\widehat{H}| \varphi_{(-) 3}\right\rangle=a_{1} b_{3} \sigma_{\mathrm{O}}, \\
& Q_{31}^{(-) 3}=\left\langle\varphi_{(-) 1}|\widehat{H}| \varphi_{(-) 3}\right\rangle=b_{1} b_{3} \sigma_{\mathrm{O}} .
\end{aligned}
$$

The second order member $\left(q_{(+) \mathrm{N},(-) 1}^{(2)}\right)$ of the power series for $q_{(+) \mathrm{N},(-) 1}$ follows from Eq. (1) and contains the direct interaction $G_{(1) \mathrm{N} 1}$ only. This term does not depend either on the presence of the lone electron pairs of the oxygen atom or on their coordination by a subsidiary cation $\left(\mathrm{E}^{+}\right)$. The relevant third order correction $\left(q_{(+) \mathrm{N},(-) 1}^{(3)}\right)$ results from Eq. (2) and involves both the direct interaction $G_{(1) \mathrm{N} 1}$ and the respective indirect interaction $G_{(2) \mathrm{N} 1}$. The lone pair orbitals of the oxygen atom are not among efficient mediators of the latter interaction, as no direct overlap of a non-negligible absolute value is feasible between the $\mathrm{HAO} \chi_{\mathrm{O} 3}$ and the orbital $\varphi_{(+) N}$. Hence, the lone electron pairs (both isolated and coordinated) hardly exert any influence upon the third order charge transfer.

Let us consider now the fourth order correction $q_{(+) \mathrm{N},(-) 1}^{(4)}$ of the same series defined by Eq. (3). As already mentioned, the lone pair orbitals do not participate as mediators in the second order interaction $G_{(2) \mathrm{N} 1}$. Thus, the last term of the right-hand side of Eq. (3) may be excluded from consideration. The direct interaction $G_{(1) \mathrm{N} 1}$ results from Eqs. (5) and (20) and proves to be a positive quantity. Thus, the total third order interaction inside the square brackets of Eq. (3) remains to be analysed.

Let us start with the case of isolated lone pair orbitals. Let the partial contribution of the doubleoccupied orbital $\chi_{\mathrm{O} 3}$ to the term $\frac{1}{2}\left(G_{(1)} G_{(1)}^{+} G_{(1)}\right)_{\mathrm{N} 1}$ be denoted by $\Delta G_{(3) \mathrm{N} 1}^{(\mathrm{O} 3)}$. Using Eqs. (5) and (20), this contribution is expressible as

$$
\begin{aligned}
\Delta G_{(3) \mathrm{N} 1}^{(\mathrm{O} 3)}= & \frac{1}{2} G_{(1) \mathrm{N} 1}\left(G_{(1) 31}^{(\mathrm{O} 3)}\right)^{2}= \\
& \frac{a_{1} b_{1}^{2} \tau \sigma_{\mathrm{O}}^{2}}{2\left(\alpha_{\mathrm{O}}-\varepsilon_{(-) 1}\right)^{2}\left(\alpha_{\mathrm{N}}-\varepsilon_{(-) 1}\right)},
\end{aligned}
$$

where $G_{(1) 31}^{(\mathrm{O} 3)}$ stands for the direct interaction between the initially-occupied $\mathrm{HAO} \chi_{\mathrm{O} 3}$ and the orbital $\varphi_{(-) 1}$. Contribution of the same $\mathrm{HAO} \chi_{\mathrm{O} 3}$ to the third order interaction $G_{(3) \mathrm{N} 1}$ will be accordingly denoted by $G_{(3) \mathrm{N} 1}^{(\mathrm{O} 3)}$. Two pairs of basis orbitals, namely $\varphi_{(+) 1}, \chi_{\mathrm{O} 3}$ and $\varphi_{(-) 1}, \chi_{\mathrm{O} 3}$, should be considered as mediators here. The increments of these pairs follow from the first, 
fourth, and fifth fractions of the definition of $G_{(3) i j}$ of Eq. (7). We then obtain

$$
\begin{aligned}
& G_{(3) \mathrm{N} 1}^{(\mathrm{O} 3)}=-\frac{1}{\alpha_{\mathrm{N}}-\varepsilon_{(-) 1}} \\
& \times\left\{\frac{S_{\mathrm{N} 1} S_{13}^{(\mathrm{O} 3)} R_{31}^{(\mathrm{O} 3)}}{\left(\varepsilon_{(+) 1}-\varepsilon_{(-) 1}\right)\left(\alpha_{\mathrm{O}}-\varepsilon_{(-) 1}\right)}-\frac{R_{\mathrm{N} 1}\left(R_{31}^{(\mathrm{O} 3)}\right)^{2}}{\left(\alpha_{\mathrm{O}}-\varepsilon_{(-) 1}\right)}\right. \\
& \left.\quad \times\left[\frac{1}{\alpha_{\mathrm{O}}-\varepsilon_{(-) 1}}+\frac{1}{\alpha_{\mathrm{N}}-\varepsilon_{(-) 1}}\right]\right\} .
\end{aligned}
$$

Now, no more is required as to substitute Eq. (20) into Eq. (22) and to form the sum $G_{(3) \mathrm{N} 1}^{(\mathrm{O} 3)}+\Delta G_{(3) \mathrm{N} 1}^{(\mathrm{O} 3)}$ designated by $\widetilde{G}_{(3) \mathrm{N} 1}^{(\mathrm{O} 3)}$. We obtain

$$
\begin{aligned}
& \widetilde{G}_{(3) \mathrm{N} 1}^{(\mathrm{O} 3)}=-\frac{a_{1} b_{1}^{2} \tau \sigma_{\mathrm{O}}^{2}}{\alpha_{\mathrm{N}}-\varepsilon_{(-) 1}} \\
& \times\left[\frac{1}{\left(\varepsilon_{(+) 1}-\varepsilon_{(-) 1}\right)\left(\alpha_{\mathrm{O}}-\varepsilon_{(-) 1}\right)}+\frac{1}{2\left(\alpha_{\mathrm{O}}-\varepsilon_{(-) 1}\right)^{2}}\right. \\
& \left.\quad+\frac{1}{\left(\alpha_{\mathrm{N}}-\varepsilon_{(-) 1}\right)\left(\alpha_{\mathrm{O}}-\varepsilon_{(-) 1}\right)}\right] .
\end{aligned}
$$

It is seen that the sum $\widetilde{G}_{(3) \mathrm{N} 1}^{(\mathrm{O} 3)}$ is a negative quantity. The same then refers to the increment of the isolated lone electron pair $\chi_{\mathrm{O} 3}$ to the fourth order partial transferred population between orbitals $\varphi_{(+) \mathrm{N}}$ and $\varphi_{(-) 1}$. The negative sign of the latter, in turn, gives rise to a certain reduction of the extent of the charge transfer between nucleophile and the $\operatorname{ABO} \varphi_{(-) 1}$ as compared to its primary value represented by the positive second order term $q_{(+) \mathrm{N},(-) 1}^{(2)}$. Thus, a suppressing influence of an isolated lone electron pair upon the above-mentioned charge transfer follows.

Let us assume now that our lone pair orbital $\chi_{\mathrm{O} 3}$ is coordinated by a subsidiary cation $\left(\mathrm{E}^{+}\right)$as described in Section 3 and consider the effects of the $\operatorname{BBO} \varphi_{(+) 3}$ and of the $\mathrm{ABO} \varphi_{(-) 3}$ separately. Let us begin with the increments of the $\mathrm{BBO} \varphi_{(+) 3}$ and denote them by a superscript (+)3 as previously (see Eq. (17)). As with terms of Eqs. (16) and (17), the new increments $\Delta G_{(3) \mathrm{N} 1}^{(+) 3}$ and $G_{(3) \mathrm{N} 1}^{(+) 3}$ differ from their analogues of Eqs. (21) and (22) in two respects: first, the factor $a_{3}^{2}$ arises in the numerator of expressions for both $\Delta G_{(3) \mathrm{N} 1}^{(+) 3}$ and $G_{(3) \mathrm{N} 1}^{(+) 3}$ and, second, the former energy interval $\alpha_{O}-\varepsilon_{(-) 1}$ is replaced by $\varepsilon_{(+) 3}-\varepsilon_{(-) 1}$. Thus, differences between shapes and one-electron energies of orbitals $\varphi_{(+) 3}$ and
$\chi_{\mathrm{O} 3}$ manifest themselves once again. Instead of Eq. (23) we then obtain

$$
\begin{aligned}
& \widetilde{G}_{(3) \mathrm{N} 1}^{(+) 3}=-\frac{a_{1} a_{3}^{2} b_{1}^{2} \tau \sigma_{\mathrm{O}}^{2}}{\alpha_{\mathrm{N}}-\varepsilon_{(-) 1}} \\
& \times\left[\frac{1}{\left(\varepsilon_{(+) 1}-\varepsilon_{(-) 1}\right)\left(\varepsilon_{(+) 3}-\varepsilon_{(-) 1}\right)}+\frac{1}{2\left(\varepsilon_{(+) 3}-\varepsilon_{(-) 1}\right)^{2}}\right. \\
& \left.\quad+\frac{1}{\left(\alpha_{\mathrm{N}}-\varepsilon_{(-) 1}\right)\left(\varepsilon_{(+) 3}-\varepsilon_{(-) 1}\right)}\right]
\end{aligned}
$$

A lowered absolute value of the new interaction $\widetilde{G}_{(3) \mathrm{N} 1}^{(+) 3}$ versus that of $\widetilde{G}_{(3) \mathrm{N} 1}^{(\mathrm{O} 3)}$ easily follows from comparison of Eqs. (23) and (24). Meanwhile, the negative sign is preserved when passing from $\widetilde{G}_{(3) \mathrm{N} 1}^{(\mathrm{O} 3)}$ to $\widetilde{G}_{(3) \mathrm{N} 1}^{(+) 3}$. Consequently, the absolute value of the relevant negative fourth order increment to the partial transferred population $q_{(+) \mathrm{N},(-) 1}$ also is decreased after coordination. Hence, the suppressing influence of a lone pair orbital upon the extent of charge transfer from nucleophile to the $\mathrm{C}=\mathrm{O}$ bond becomes reduced after introducing a subsidiary cation $\left(\mathrm{E}^{+}\right)$. We may also conclude the above effect to originate from characteristic changes in the shape and one-electron energy of the lone pair orbital after its coordination with the subsidiary ion as it was the case with the polarity of the $\mathrm{C}=\mathrm{O}$ bond (Section 3).

Let us turn finally to contributions of the $\mathrm{ABO} \varphi_{(-) 3}$. The increment $\Delta G_{(3) \mathrm{N} 1}^{(-) 3}$ originating from the second term of the square brackets of Eq. (3) vanishes and, consequently, the total contribution $\widetilde{G}_{(3) \mathrm{N} 1}^{(-) 3}$ coincides with $G_{(3) \mathrm{N} 1}^{(-) 3}$. Orbitals $\varphi_{(+) 1}$ and $\varphi_{(-) 3}$ mediate the latter increment. To derive the expression concerned, the second and third fractions of Eq. (7) should be considered. The result is as follows:

$$
\begin{aligned}
& \widetilde{G}_{(3) \mathrm{N} 1}^{(-) 3}=G_{(3) \mathrm{N} 1}^{(-) 3}=\frac{S_{\mathrm{N} 1} R_{13}^{(-) 3} Q_{31}^{(-) 3}}{\left(\varepsilon_{(+) 1}-\varepsilon_{(-) 3}\right)\left(\alpha_{\mathrm{N}}-\varepsilon_{(-) 1}\right)} \\
& \times\left[\frac{1}{\varepsilon_{(+) 1}-\varepsilon_{(-) 1}}+\frac{1}{\alpha_{\mathrm{N}}-\varepsilon_{(-) 3}}\right] .
\end{aligned}
$$

After invoking Eq. (20), we obtain the final expression for $\widetilde{G}_{(3) \mathrm{N} 1}^{(-) 3}$, viz.

$$
\widetilde{G}_{(3) \mathrm{N} 1}^{(-) 3}=\frac{a_{1} b_{1}^{2} b_{3}^{2} \tau \sigma_{\mathrm{O}}^{2}}{\left(\alpha_{\mathrm{N}}-\varepsilon_{(-) 1}\right)\left(\varepsilon_{(+) 1}-\varepsilon_{(-) 3}\right)} \times
$$




$$
\times\left[\frac{1}{\varepsilon_{(+) 1}-\varepsilon_{(-) 1}}+\frac{1}{\alpha_{N}-\varepsilon_{(-) 3}}\right] .
$$

It is seen that $\widetilde{G}_{(3) \mathrm{N} 1}^{(-) 3}$ is a positive quantity. The same then refers to the relevant fourth order term $q_{(+) \mathrm{N},(-) 1}^{(4)}$. Thus, formation of an antibonding orbital $\varphi_{(-) 3}$ stimulates the charge transfer from nucleophile to the bent bond under attack.

Comparison of effects of the $\mathrm{BBO} \varphi_{(+) 3}$ and of the $\operatorname{ABO} \varphi_{(-) 3}$ allows us then to conclude that the total influence of coordination of a lone electron pair of the oxygen atom by a subsidiary cation consists in strengthening of the charge transfer from nucleophile to the $\mathrm{C}=\mathrm{O}$ bond. This implies an enhanced relative reactivity of the coordinated reactant. The origin of this effect closely resembles that of the increased polarity of the $\mathrm{C}=\mathrm{O}$ bond (Section 3).

\section{Effects of substituents upon the extent of charge transfer between nucleophile and the $\mathrm{C}=\mathrm{O}$ bond}

In this section, we are about to replace a $\mathrm{C}_{\alpha}-$ $\mathrm{H}$ or $\mathrm{C}_{\alpha}-\mathrm{C}_{\beta}$ bond of our carbonyl compound by a heteroatom-containing $\left(\mathrm{C}_{\alpha}-\mathrm{Z}\right)$ bond and consider the consequent effects upon the charge transfer from the orbital $\varphi_{(+) \mathrm{N}}$ to the $\mathrm{ABO} \varphi_{(-) 1}$.

Let us start with the parent $\mathrm{C}_{\alpha}-\mathrm{H}$ or $\mathrm{C}_{\alpha}-\mathrm{C}_{\beta}$ bond. Since uniform Coulomb parameters are usually ascribed to $\mathrm{sp}^{3}$-HAOs of carbon atoms and to $1 \mathrm{~s}_{\mathrm{H}} \mathrm{AOs}$ of hydrogen atoms [40], a single model may be constructed for both cases. To this end, let a certain orbital $\chi_{\beta}$ represent the $\mathrm{H}$ and/or $\mathrm{C}_{\beta}$ atoms so that the orbitals $\chi_{\mathrm{C} 4}$ and $\chi_{\beta}$ build up our parent bond. Let these orbitals be described by the Coulomb parameter $\alpha_{\mathrm{C}}$ coinciding with our energy reference point (Section 2). The bond itself will be characterized by the resonance parameter $\beta_{\mathrm{CC}}$, as well as by BOs $\varphi_{(+) 4}^{(\mathrm{p})}$ and $\varphi_{(-) 4}^{(\mathrm{p})}$, where the superscript $(\mathrm{p})$ here and below refers to the parent bond. One-electron energies of these BOs will be denoted by $\varepsilon_{(+) 4}^{(\mathrm{p})}$ and $\varepsilon_{(-) 4}^{(\mathrm{p})}$, respectively (These coincide with $+\beta_{\mathrm{CC}}$ and $\left.-\beta_{\mathrm{CC}}\right)$. The orbitals themselves will be defined by Eqs. (9)-(11), where $a_{4}^{(\mathrm{p})}$ and $b_{4}^{(\mathrm{p})}$ coincide with $1 / \sqrt{2}$. The resonance parameter between HAOs $\chi_{\mathrm{C} 4}$ and $\chi_{\mathrm{C} 1}$ will be denoted by $\sigma_{\mathrm{C}}$, whilst that between orbitals $\varphi_{(+) \mathrm{N}}$ and $\chi_{\mathrm{C} 4}$ will acquire the designation $\mu$, i. e.

$$
\left\langle\chi_{\mathrm{C} 4}|\widehat{H}| \chi_{\mathrm{C} 1}\right\rangle=\sigma_{\mathrm{C}}, \quad\left\langle\chi_{\mathrm{C} 4}|\widehat{H}| \varphi_{(+) \mathrm{N}}\right\rangle=\mu .
$$

Let us assume now that the $\mathrm{H}\left(\mathrm{C}_{\beta}\right)$ atom of the parent bond is replaced by a certain heteroatom $\mathrm{Z}$. Let us dwell first on heteroatoms that exert inductive electronaccepting effects only. In this connection, emergence of this new atom will be modelled by an alteration in the Coulomb parameter of the orbital $\chi_{\beta}$. New bond orbitals $\varphi_{(+)}$and $\varphi_{(-) 4}$ will then contain non-uniform coefficients $a_{4}$ and $b_{4}$ resulting from Eq. (10), where $a_{4}>b_{4}$. The modified one-electron energies will be accordingly designated by $\varepsilon_{(+) 4}^{(Z)}$ and $\varepsilon_{(-) 4}^{(Z)}$. The resonance parameters $\sigma_{\mathrm{C}}$ and $\mu$ are not assumed to be influenced by introduction of the heteroatom.

The second order contribution to the charge transfer from the orbital $\varphi_{(+) \mathrm{N}}$ to the $\mathrm{ABO} \varphi_{(-) 1}$ does not depend on characteristics of the $\mathrm{C}_{\alpha}-\mathrm{H}\left(\mathrm{C}_{\alpha}-\mathrm{Z}\right)$ bond. The relevant third order correction $q_{(+) \mathrm{N},(-) 1}^{(3)}$ contains a product of the positive direct interaction $G_{(1) \mathrm{N} 1}$ and of the indirect interaction $G_{(2) \mathrm{N} 1}$. The latter is expected to be mediated by orbitals of either $\mathrm{C}_{\alpha}-\mathrm{H}\left(\mathrm{C}_{\alpha}-\mathrm{C}_{\beta}\right)$ or $\mathrm{C}_{\alpha^{-}}$ $\mathrm{Z}$ bonds. Thus, the effect of the substituent $\mathrm{Z}$ is likely to manifest itself just within the third order increment $q_{(+) \mathrm{N},(-) 1}^{(3)}$. Let us consider the relevant expressions in a more detail.

The increment of orbitals of the $\mathrm{C}_{\alpha}-\mathrm{H}\left(\mathrm{C}_{\alpha}-\mathrm{Z}\right)$ bonds to the second order interaction $G_{(2) \mathrm{N} 1}$ follows from Eq. (6) for $m=4$ and $r=4$. In the case of the parent bond, resonance parameters contained within this expression are

$$
\begin{array}{ll}
S_{\mathrm{N} 4}^{(\mathrm{p})}=\frac{1}{\sqrt{2}} \mu, & R_{41}^{(\mathrm{p})}=-\frac{a_{1} \sigma_{\mathrm{C}}}{\sqrt{2}}, \\
R_{\mathrm{N} 4}^{(\mathrm{p})} & =-\frac{\mu}{\sqrt{2}}, \quad Q_{41}^{(\mathrm{p})}=\frac{a_{1} \sigma_{\mathrm{C}}}{\sqrt{2}}
\end{array}
$$

and yield the result given below:

$$
\begin{aligned}
& G_{(2) \mathrm{N} 1}^{(\mathrm{p})}=\frac{a_{1} \sigma_{\mathrm{C}} \mu}{\alpha_{\mathrm{N}}-\varepsilon_{(-) 1}} \\
& \times\left[-\frac{1}{2\left(\varepsilon_{(+) 4}^{(\mathrm{p})}-\varepsilon_{(-) 1}\right)}+\frac{1}{2\left(\alpha_{\mathrm{N}}-\varepsilon_{(-) 4}^{(\mathrm{p})}\right)}\right] .
\end{aligned}
$$

The first (negative) increment of this expression originates from the mediating effect of the $\operatorname{BBO} \varphi_{(+) 4}^{(\mathrm{p})}$, whilst the second (positive) one represents the effect of the $\operatorname{ABO} \varphi_{(-) 4}^{(\mathrm{p})}$. An analogous conclusion refers also to the final expression for the total third order transferred population $q_{(+) \mathrm{N},(-) 1}^{(3)}$. It is also noteworthy here that the same signs of partial increments have been established when analysing the fourth order term $q_{(+) \mathrm{N},(-) 1}^{(4)}$ 
of Sec. 4, namely a negative increment of initiallyoccupied (bonding) orbitals $\left(\varphi_{(+) 3}\right.$ and/or $\left.\chi_{\mathrm{O} 3}\right)$ was accompanied there by a positive increment of the initiallyvacant (antibonding) orbital $\left(\varphi_{(-) 3}\right)$.

In the case of a $\mathrm{C}_{\alpha}-\mathrm{Z}$ bond, we accordingly obtain

$$
\begin{aligned}
& S_{\mathrm{N} 4}^{(\mathrm{Z})}=b_{4} \mu, \quad R_{41}^{(\mathrm{Z})}=-a_{1} b_{4} \sigma_{\mathrm{C}}, \\
& R_{\mathrm{N} 4}^{(\mathrm{Z})}=-a_{4} \mu, \quad Q_{41}^{(\mathrm{Z})}=a_{1} a_{4} \sigma_{\mathrm{C}}
\end{aligned}
$$

instead of Eq. (28) and

$$
\begin{aligned}
& G_{(2) \mathrm{N} 1}^{(\mathrm{Z})}=\frac{a_{1} \sigma_{\mathrm{C}} \mu}{\alpha_{\mathrm{N}}-\varepsilon_{(-) 1}} \\
& \times\left[-\frac{b_{4}^{2}}{\varepsilon_{(+) 4}^{(\mathrm{Z})}-\varepsilon_{(-) 1}}+\frac{a_{4}^{2}}{\alpha_{\mathrm{N}}-\varepsilon_{(-) 4}^{(\mathrm{Z})}}\right]
\end{aligned}
$$

instead of Eq. (29). Let us invoke also the following relations

$$
\begin{aligned}
& a_{4}^{2}>\frac{1}{2}, \quad b_{4}^{2}<\frac{1}{2}, \\
& \left|\varepsilon_{(+) 4}^{(\mathrm{Z})}-\varepsilon_{(-) 1}\right|>\left|\varepsilon_{(+) 4}^{(\mathrm{p})}-\varepsilon_{(-) 1}\right|, \\
& \left|\alpha_{\mathrm{N}}-\varepsilon_{(-) 4}^{(\mathrm{Z})}\right|<\left|\alpha_{\mathrm{N}}-\varepsilon_{(-) 4}^{(\mathrm{p})}\right|
\end{aligned}
$$

resulting from Eqs. (10) and (11) and from Fig. 2. It is seen that the absolute value of the negative increment of the $\mathrm{BBO}$ of the bond under consideration becomes reduced in Eq. (31) versus that of Eq. (29), whilst the positive contribution of the $\mathrm{ABO}$ is accordingly increased. Owing to the positive sign of the factor $G_{(1) \mathrm{N} 1}$, the same conclusion refers to the relative absolute values of the relevant two increments of the third order partial transferred population $q_{(+) \mathrm{N},(-) 1}^{(3)}$. As a result, the latter increases after introducing the heteroatom. Thus, the overall charge transfer from nucleophile to the $\mathrm{C}=\mathrm{O}$ bond is predicted to grow after substitution of a hydrogen (carbon) atom by a more electronegative heteroatom. This, in turn, implies an enhanced relative reactivity of the substituted compound versus the parent reactant in accordance with experimental trends (Sec. 1).

The above-drawn conclusion is based on opposite signs of the two increments of Eqs. (29) and (31) and on relations of Eq. (32). The first of these factors may be traced back to opposite signs of contributions of BBOs and of ABOs in general to the indirect interorbital interactions $G_{(2) i j}$ of Eq. (6). The inequalities (32), in turn, represent specific alterations in the shapes and oneelectron energies of BOs of the mediating bond after in- troducing a more electronegative atom. These changes are as follows: the 'centre of gravity' of the bonding BO is shifted away from the reacting bond, whilst that of the $\mathrm{ABO}$ becomes accordingly nearer; furthermore, the $\mathrm{ABO}$ of the mediating bond approaches the orbital of the reagent (nucleophile), whilst the respective BBO is removed away from the electron-accepting orbital of the reacting bond in the scale of one-electron energies. These changes evidently are rather universal in their nature. It is no surprise, therefore, that an analogous mechanism was found to determine also the enhanced reactivity of $\alpha$-halocarbonyl compounds versus that of allyl halogenides in the $S_{N} 2$ reactions [23].

Let us turn finally to substituents containing lone electron pairs that exert electron-donating effects upon the remaining fragments, e.g. $\mathrm{NR}_{2}$, OR, etc. To analyse this case, the above-studied model will be supplemented by an additional initially-occupied orbital $\varphi_{(+) \text {D }}$ representing the lone electron pair of our substituent (the actual nature of this new orbital - either a $2 \mathrm{p}_{z} \mathrm{AO}$ or an $\mathrm{sp}^{3}$-hybrid $\mathrm{AO}-$ is not essential here). Let us define the following resonance parameters,

$$
\begin{gathered}
\left\langle\varphi_{(+) \mathrm{D}}|\widehat{H}| \varphi_{(+) \mathrm{N}}\right\rangle=\nu>0, \\
\left\langle\varphi_{(+) \mathrm{D}}|\widehat{H}| \chi_{\mathrm{C} 1}\right\rangle=\lambda>0,
\end{gathered}
$$

along with the relevant Coulomb parameter $\alpha_{\mathrm{D}}$. It is evident that the orbital $\varphi_{(+)}$D playes the role of an additional mediator of the indirect interaction $G_{(2) \mathrm{N} 1}$. The resulting increment to the interaction $G_{(2) \mathrm{N} 1}$ is expressible as

$$
G_{(2) \mathrm{N} 1}^{(\mathrm{D})}=-\frac{a_{1} \lambda \nu}{\left(\alpha_{\mathrm{N}}-\varepsilon_{(-) 1}\right)\left(\alpha_{\mathrm{D}}-\varepsilon_{(-) 1}\right)}<0,
$$

and proves a negative quantity. As a result, the lone pair orbital $\varphi_{(+) \mathrm{D}}$ yields a certain reduction of the overall charge transfer between nucleophile and the $\mathrm{C}=\mathrm{O}$ bond. Thus, a suppression of relative reactivity follows from our model for donor-containing compounds. Moreover, the lower is the absolute value of the parameter $\alpha_{\mathrm{D}}$, the more extended is the reduction. An analogous extinction of the relative reactivity is observed experimentally when the electron-donating ability of the substituent grows, e. g. within the series of substituents: $\mathrm{H}>\mathrm{Hal}>\mathrm{OR}>\mathrm{NR}_{2}[8]$.

\section{Conclusions}

The principal achievement of the above study consists in constructing an abstract model of $\mathrm{Ad}_{\mathrm{N}} 2$ processes of carbonyl compounds. The model is based 
on a combination of the concept of bent bonds, of the semilocalized approach to chemical reactivity, and of the Hückel type approximation for Hamiltonian matrix elements. Adequacy of the new model is verified by comparison of the results obtained to experimental trends. In particular, an enhanced relative reactivity versus the relevant parent compound is predicted for the reactant, a lone electron pair of the oxygen atom of which is coordinated by a subsidiary cation (electrophile), as well as for a substituted compound containing a more electronegative heteroatom instead of the $\mathrm{C}_{\beta}$ atom. Meanwhile, a suppressed relative reactivity of the derivative is expected if the substituent is characterized by an electron-donating effect. The same conclusions follow also from analysis of experimental facts.

The results of the present study contribute to our understanding of the mechanism of $\mathrm{Ad}_{\mathrm{N}} 2$ reactions of carbonyl compounds in comparison to related processes. In this respect, the main achievements are as follows:

1. Interrelations (parallelisms) are revealed between different aspects of the $\mathrm{Ad}_{\mathrm{N}} 2$ process. In particular, a real parallelism is observed between the effects of a subsidiary cation upon the overall polarity of the initial $\mathrm{C}=\mathrm{O}$ bond and upon the subsequent charge transfer from nucleophile to the reacting bent bond. This implies a concerted manifestation of both static and dynamic factors to underly the relevant reaction mechanism. An analogous parallelism manifests itself also between influences of a subsidiary cation and of an electron-accepting substituent (the latter replacing the $\mathrm{C}_{\beta}$ atom of the carbonyl compound) upon the charge transfer from nucleophile to the reacting $\mathrm{C}-\mathrm{O}$ bond. The fact that the populations transferred are determined by terms of different orders for the cases of the cation and of the substituent (viz. by the fourth and third order ones, respectively) makes the above-mentioned parallelism even more surprising.

2. A certain universal mechanism is shown to underly the neighbourhood-determined effects upon relative reactivities of carbonyl compounds. This conclusion is based on the following two points: (i) external groups participate in the decisive charge transfer between the orbital of nucleophile and the antibonding orbital of the reacting bond indirectly by offering their orbitals as mediators in the respective interorbital interaction and (ii) an indirect participation of a bonding (initially-occupied) orbital of a certain neighbouring group always contributes to lowering of the charge transfer, whereas participation of an antibonding (initially-vacant) orbital gives rise to an opposite effect. As a result, a suppression of the charge transfer and thereby of the relative reactivity automatically follows after replacement of the $\mathrm{C}_{\beta}$ atom of the carbonyl compound by an electron-donating substituent represented by a single double-occupied orbital. Meanwhile, an introduction of an electron-accepting subsystem (both of a cation and of an electronaccepting substituent) is accompanied by an increase of both charge transfer and relative reactivity. The origin of the latter effect consists in a shift of the bonding orbital away from the reaction centre and in a simultaneous approach of the antibonding orbital.

3. Additional arguments are given for the analogy between early stages of the $\mathrm{Ad}_{\mathrm{N}} 2$ reaction of carbonyl compounds and of the $\mathrm{S}_{\mathrm{N}} 2$ process of substituted alkanes. These arguments are as follows: (i) predominance of the secondary polarization of the reacting bond over its depolarization due to the attack of nucleophile ensures a shift of the relevant pair of electrons towards the more electronegative atom of the reacting bond during early stages of both processes and (ii) similar mechanisms underly the influences of electron-accepting substituents upon the extents of charge transfer from nucleophile to the reacting bonds.

The results obtained contribute also to developement of models of organic reactions in general. The following points are demonstrated in the present study:

1. Advantages of the bent bond model for double bonds over the standard $\sigma, \pi$-model in qualitative studies of neighbourhood-determined aspects of organic processes.

2. Surprising possibilities of the Hückel model in descriptions of effects that are traditionally traced back to manifestation of the Coulomb forces (the influence of a subsidiary cation attached to a lone pair orbital of the oxygen atom upon the polarity of the $\mathrm{C}=\mathrm{O}$ bond serves as the most illustrative example here).

3. A wide scope of applicability of the semilocalized approach to chemical reactivity, including processes the reactants of which contain a double bond and neighbouring groups lying on its principal plane. 
4. Adequacy of the concept of direct (through-space) and indirect (through-bond) interactions for interpretation of chemical reactions.

\section{References}

[1] Chemical Applications of Topology and Graph Theory, ed. R.B. King (Elsevier, Amsterdam, 1983).

[2] R. Herges, Chem. Rev. 106, 4820 (2006).

[3] M.J.S. Dewar and R.C. Dougherty, The PMO Theory of Organic Chemistry (Plenum Press, New York, 1975).

[4] D.-K. Seo, G. Papoian, and R. Hoffmann, Int. J. Quantum Chem. 77, 408 (2000).

[5] L. Rincon, J. Mol. Struct. (Theochem) 731, 213 (2005).

[6] M. Edenborough, Organic Reaction Mechanisms. A Step by Step Approach (Taylor and Francis, Ltd., London, 1999).

[7] P. Laszlo, Logique de la synthese organique (Ecole Polytechnique, Paris, 1990).

[8] A.S. Dnieprovskii and T.I. Temnikova, Theoretical Fundamentals of Organic Chemistry (Khimia, Leningrad, 1991) [in Russian].

[9] M. Uemura, K. Yagi, M. Inasaki, M. Nomura, H. Yorimitsu, and K. Oshima, Tetrahedron 62, 3523 (2006).

[10] R. Gancarz, Tetrahedron 51, 10627 (1995).

[11] P. Cabon, R. Rumin, J.Y. Salaun, S. Triki, and H. Des Abbayes, Organometallics 24, 1709 (2005).

[12] A. Bogevig, K.V. Gothelf, and K.A. Jorgensen, Chem. Eur. J. 8, 5652 (2002).

[13] M. Arno, R.J. Zaragoza, and L.R. Domingo, Tetrahedron: Asymmetry 15, 1541 (2004).

[14] M. Bruvoll, T. Hansen, and E. Uggerud, J. Phys. Org. Chem. 20, 206 (2007).

[15] H. Liu and Y. Shi, J. Comput. Chem. 15, 1311 (2004).

[16] N. Tezer and R. Ozkan, J. Mol. Struct. (Theochem) 546, 79 (2001).

[17] F. Ogliaro, D.L. Cooper, and B. Karadakov, Int. J. Quantum Chem. 74, 223 (1999).

[18] F.A. Carroll, Perspectives on Structure and Mechanism in Organic Chemistry (Brooks/Cole, Pacific Grove, 1998).
[19] V. Gineityte, J. Mol. Struct. (Theochem) 588, 99 (2002).

[20] V. Gineityte, Int. J. Quantum Chem. 94, 302 (2003).

[21] V. Gineityte, J. Mol. Struct. (Theochem) 343, 183 (1995).

[22] V. Gineityte, J. Mol. Struct. (Theochem) 541, 1 (2001).

[23] V. Gineityte, J. Mol. Struct. (Theochem) 663, 47 (2003).

[24] V. Gineityte, J. Mol. Struct. (Theochem) 680, 199 (2004).

[25] E.A. Robinson and R.J. Gillespie, J. Chem. Educ. 57, 329 (1980).

[26] G.A. Gallup, J. Chem. Educ. 65, 671 (1988).

[27] J.C. Paniagua, A. Moyano, and L.M. Tel, Int. J. Quantum Chem. 26, 383 (2004).

[28] K.B. Wiberg, Acc. Chem. Res. 29, 229 (1996).

[29] M. Eckert-Maksic, Z.B. Maksic, and R. Gleiter, Theor. Chim. Acta 66, 193 (1984).

[30] W.E. Palke, J. Am. Chem. Soc. 108, 6543 (1986).

[31] P.A. Schultz and R.P. Messmer, J. Am. Chem. Soc. 110, 8258 (1988).

[32] P.A. Schultz and R.P. Messmer, J. Am. Chem. Soc. 115, 10925; 10943 (1993).

[33] R.P. Messmer and P.A. Schultz, Phys. Rev. Lett. 57, 2653 (1986).

[34] C.W. Bauschlicher, Jr. and P.R. Taylor, Phys. Rev. Lett. 60, 859 (1988).

[35] J.A. Pople and D.P. Santry, Mol. Phys. 7, 269 (1964).

[36] C. Sandorfy, Can. J. Chem. 33, 1337 (1955).

[37] H. Yoshizumi, Trans. Faraday Soc. 53, 125 (1957).

[38] V. Gineitytè, Lithuanian J. Phys. 45, 7 (2005).

[39] V. Gineityte, J. Mol. Struct. (Theochem) 585, 15 (2002).

[40] V. Gineityte, J. Mol. Struct. (Theochem) 434, 43 (1998).

[41] V. Gineityte, J. Mol. Struct. (Theochem) 713, 93 (2005).

[42] V. Gineityte, J. Mol. Struct. (Theochem) 810, 91 (2007). 


\title{
NUKLEOFILO PRIJUNGIMAS PRIE KARBONILO GRUPĖS BANANINIŲ JUNGČIUU
}

\author{
V. Gineitytè
}

Vilniaus universiteto Teorinès fizikos ir astronomijos institutas, Vilnius, Lietuva

\begin{abstract}
Santrauka
Pasiūlytas ir pritaikytas karbonilo junginių nukleofilinio prijungimo reakcijų modelis, besiremiantis bananinių jungčių koncepcija, anksčiau gautomis reaguojančios sistemos viendalelinès tankio matricos išraiškomis ir Hiukelio artiniu hamiltoniano matricai. Bazinès modelio funkcijos parinktos taip, kad jos būtų lokalizuotos ant atskiru reaguojančios sistemos cheminių jungčių. Dviguboji CO jungtis modeliuojama dviem ekvivalenčiomis bananinėmis jungtimis, kurių viena yra atakuojama nukleofilo. Gauti rezultatai pagrindžia prielaidą, kad CO jungtis tampa labiau poliarine, kai deguonies atomas yra koordinuojamas katijonu. Be to, atsiranda ga-
\end{abstract}

limybė interpretuoti šį reiškini pasitelkiant tarporbitalines sąveikas. Parodyta, jog toks pat koordinavimas sukelia ir krūvio pernešimo tarp nukleofilo ir reaguojančios $\mathrm{CO}$ jungties padidejimą vélesnėse proceso stadijose. Šie rezultatai leidžia paaiškinti rūgštinès katalizès reiškinị nagrinėjamose reakcijose. Taip pat ištirta prie anglies atomo esančių pakaitu i taka minètajam krūvio pernešimui, patvirtinant analogiją tarp nukleofilinio prijungimo prie $\mathrm{CO}$ jungties ir nukleofilinès substitucijos reakcijų alkanų dariniuose ankstyvųų stadijų. Aptarti bananinių jungčių modelio privalumai lyginant su standartiniu (sigma-pi) modeliu dviguboms jungtims. 